\title{
Neural Network Technology Forecasting the Country's Business Climate
}

\author{
Vita Los \\ Faculty of Economics \\ Zaporizhzhia National University \\ Zaporizhzhia, Ukraine \\ vitalos.2704@gmail.com
}

\author{
Dmytro Ocheretin \\ Faculty of Economics \\ Zaporizhzhia National University \\ Zaporizhzhia, Ukraine \\ odvisua@gmail.com
}

\author{
Hanna Kucherova \\ Chair of Economics \\ Classic Private University \\ Zaporizhzhia, Ukraine \\ kucherovahanna@gmail.com
}

\author{
and Olha Bilska \\ Chair of Economic Theory, Marketing \\ and International Economy \\ Classic Private University \\ Zaporizhzhia, Ukraine \\ lexusol1987@gmail.com
}

\begin{abstract}
One of the important leading indicators that show the current state of the country's economic cycle, its prospects in the near future and generally characterize the country's business climate is the business confidence index (BCI). In this paper a forecast of the business confidence index is built using neural network technology using the example of the four European countries (Germany, Hungary, Poland, Slovenia).Forecasting was carried out taking into account economic indicators that characterize the socio-economic situation in the country. The selected economic indicators based on correlation analysis and have significant relationship with the business confidence index. For forecasting, the quarterly values of economic indicators for the last 12 years (2007-2018) were taken. Also the accuracy of the obtained forecasts was also assessed and the trends of the business confidence index development are established. It was found that the accuracy of the obtained forecasts is high. It has been proven that level of the BCI in the next period will decrease by $0.41 \%$ in Germany, by $1.05 \%$ in Hungary, by $0.99 \%$ in Poland and will remain unchanged in Slovenia. The obtained forecasting results make it possible to predict changes in the business climate in a country earlier than other macroeconomic indicators. The perspectives of the research are the elaboration of a country's business climate development strategies, based on the results of the BCI forecasting.
\end{abstract}

Keywords-business climate, business confidence index, correlation analysis, socio-economic indicators, neural network modelling

\section{INTRODUCTION}

One of the challenges facing the national economy around the world is the evaluation and analysis of the country's business climate. Since the economy is developing unevenly and some cycles are available in its dynamics, it becomes necessary to identify indicators that characterize the business climate and allow it to be predicted in order to prevent crises in the country's economy.

Economy as a whole is identified as open socio-economic system, which is characterized by subjective-objective features. Therefore, when studying its business climate, one should take into account not only objective factors of influence, but also subjective ones, which in general will ensure the integrity and fullness of the study and the reliability of its results. Subjectivity is taken into account by processing a given range of business entities that simultaneously act as participants in the formation of the country's business climate and experts in assessing its condition. These assessments are defined as their business expectations.

The effect of the credibility to business confidence has two alternative measures for the entrepreneur's confidence [1]. In general, the measurement of business confidence is made through the use of indicators that take into account market research on the economy behaviour. The first measure is the business confidence index (BCI) available from the Organisation for Economic Co-operation and Development (OECD). This index is based on the evaluations of entrepreneurs considering factors such as production, orders, inventories, the current economic situation and business entities expectations regarding the change in the immediate future. The business confidence index is a mean of the balances of the current business situation and the expectations.

A second measure for the entrepreneur's confidence is the industry confidence index (ICI), which based on a monthly survey of directors of large, medium, and small industrial companies. This survey considers the following questions: current level of global demand, current inventory levels, current business situation, expected production, expected employment, and the expected business situation.

Helder Ferreira de Mendonçaand André Filipe Guedes Almeida [1] has constructed credibility index on the base of inflation target of Brazil. The impact of the credibility of monetary policy on business confidence is significant for decision making by entrepreneurs. But business confidence may be influenced by other factors, which do not necessarily relate to the credibility of monetary policy under inflation targeting. 
In the investigation [2] proposed on the base of text data from newspaper articles generation local business confidence indices and analysis local inter-industry relations using the contact histories of local banks. Framework uses a learned bidirectional long short-term memory (BiLSTM) model is generating business confidence indices from banks' contact histories and then analysis inter-industry relations.

The business confidence index is indicator, which supposed to provide prognostic capabilities for future changes in the economic outlook. S. Feuerriegela and J. Gordon [3] include this indicator in the set of macroeconomic indicators with the aim of reflecting the general German economic climate. Forecasting macroeconomic indicators happens with the help of the semantic path model.

In the paper [4] a forecast of the business confidence index of Ukraine and four European countries (Germany, Hungary, Poland and Slovenia) is implemented, based on the regression models. The possibility of constructing the business confidence index based on economic indicators, which characterize current economic activity of the country. In addition to multiple regression models, artificial neural networks are actively used in time series prediction [5]. It is

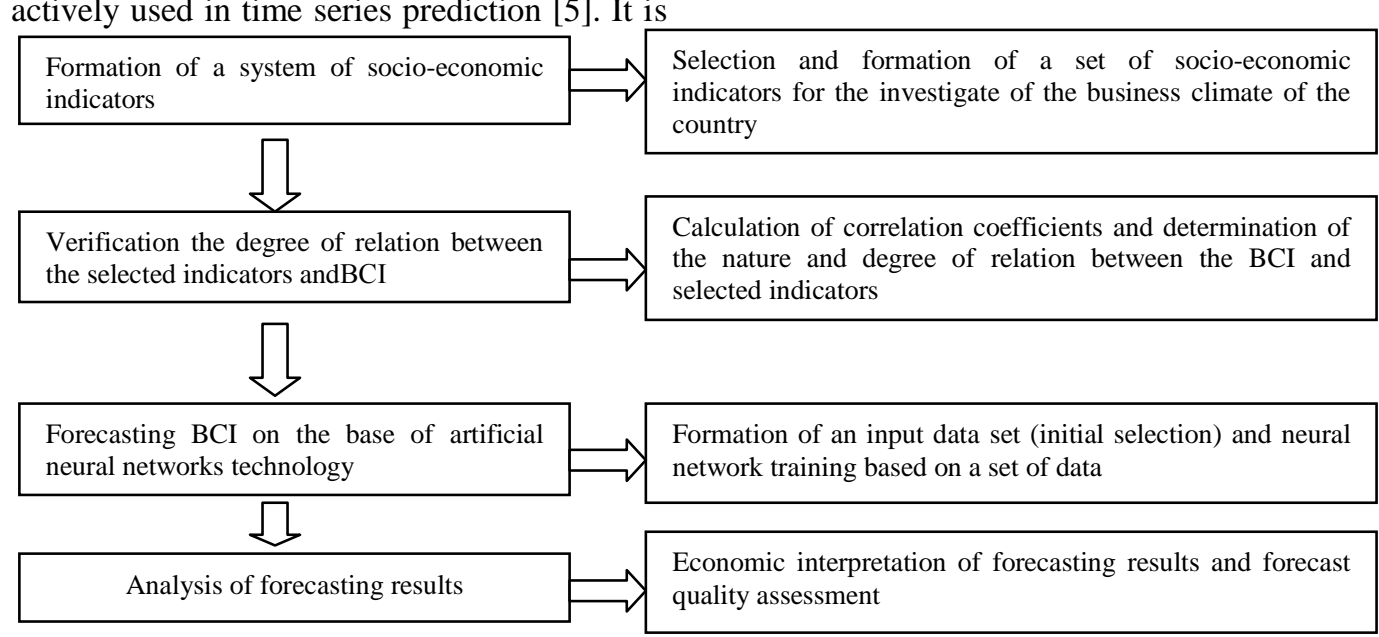

Fig. 1. Methodical approach to forecasting of BCI using artificial neural networks

In accordance with the proposed methodological approach, the first stage is the formation of a system of socio-economic indicators that characterize the business climate of the investigated country. Based on the analysis of scientific papers [8], we made an assumption that the business confidence index (BCI) [6] is influenced by a number of socio-economic indicators, such as: Producer Price, Unemployment Rate, GDP Annual Growth Rate, New Orders, Consumer Spending, Changes in Inventories, Exports, Imports, Industrial Production and Steel Production [7]. Accordingly, we have formed an array of input data for each investigated country. Input data is a time series of quarterly growth rates of economic indicators over the past twelve years (2007-2018).

At the second stage, the degree of relation between the selected socio-economic indicators and the $\mathrm{BCI}$ is verified. The degree of relation is established using a correlation coefficient. If its value is equal to or greater than 0.7 , then we will use this indicator in the future when forecasting BCI. All this approach that is proposed to be used for predicting BCI, given its accuracy and broad research capabilities.

\section{MethodicAl APPROACH TO CONSTRUCTION AND FORECAST OF BUSINESS CONFIDENCE INDEX}

In this paper forecasting of business confidence index was carried out on the example of the four European countries, such as Germany, Hungary, Poland and Slovenia. These countries were selected to compare and analyse the business climate of one of the most developed European countries and countries that are developing. It should also be noted that the last three countries are the western neighbours of Ukraine, which are beginning, gradually, to argue as an important component of the European Union. We have chosen the secondary data for our forecasting of the business confidence index, obtained from official statistic data of Organisation for Economic Co-operation and Development (OECD) [6] and data site "Trading Economics" [7].

Authors propose methodical approach to forecasting of BCI using artificial neural networks, which presented in the Figure 1.
Selection and formation of a set of socio-economic indicators for the investigate of the business climate of the country

Calculation of correlation coefficients and determination of the nature and degree of relation between the BCI and selected indicator

Formation of an input data set (initial selection) and neural network training based on a set of data

Economic interpretation of forecasting results and forecas quality assessmen

other indicators whose correlation coefficient is less than 0.7 are not considered.

The third stage is the forecast of the BCI. On the basis of the training set formed at the second stage, the neural network is trained. For the predictive neural network, the number of inputs depends on the generated array of the training set, and the output is only one - the value of BCI. Next, select the type of neural network and the method of its training. Also at this stage, the neural network is tested and launched to develop predictive values.

And at the last fourth stage the analysis of the obtained results is carried out, namely, the accuracy and quality of the developed forecast is established. The quality of the forecast is determined on the basis of confidence intervals and is visually shown in the dispersion diagram. The measure of the forecast is set using the following indicators: average train error, average test error, mean squared error (MSE) and absolute percentage error (MAPE). 
All calculations were carried out on the basis of the analytical platform Deductor Studio Academic 5.3 [9], which allows you to perform all the steps of data mining from their loading and visualization to building and evaluating the quality of finished models. The forecasting procedure, in the first place, provides for the construction of a neural network model, the determination of confidence intervals and the comparison of the predicted values of the BCI with the real ones (Table I).

The time period for analysis is $1^{\text {st }}$ quarter of $2007-4^{\text {th }}$ quarter of 2018. The training set consists of $90 \%$ of the data (43 values, time period between $1^{\text {st }}$ quarter of 2007 and $3^{\text {rd }}$ quarter of 2017), and the test set $-10 \%$ of data (5 values, time period between $4^{\text {th }}$ quarter of 2017 and $4^{\text {th }}$ quarter of
2018). An artificial neural network consists of one hidden layer, which contains two neurons, and one output layer (business confidence index). The number of variables in the input layer corresponds to the number of selected economic indicators for modelling. The activation function of the hidden layer is the sigmoid function. This type of function is often used for modelling and the outgoing values of such a function continuously fill the range from 0 to 1 [10]. The learning algorithm is the back-propagation error algorithm (Back-Propagation) with a learning rate of 0.1 . The difference between the reference and the real output of the network is less than 0.05 (learning rate). The number of learning iterations is 10000 .

TABLE I. THE RESULTS OF THE NEURAL NETWORK TECHNOLOGY

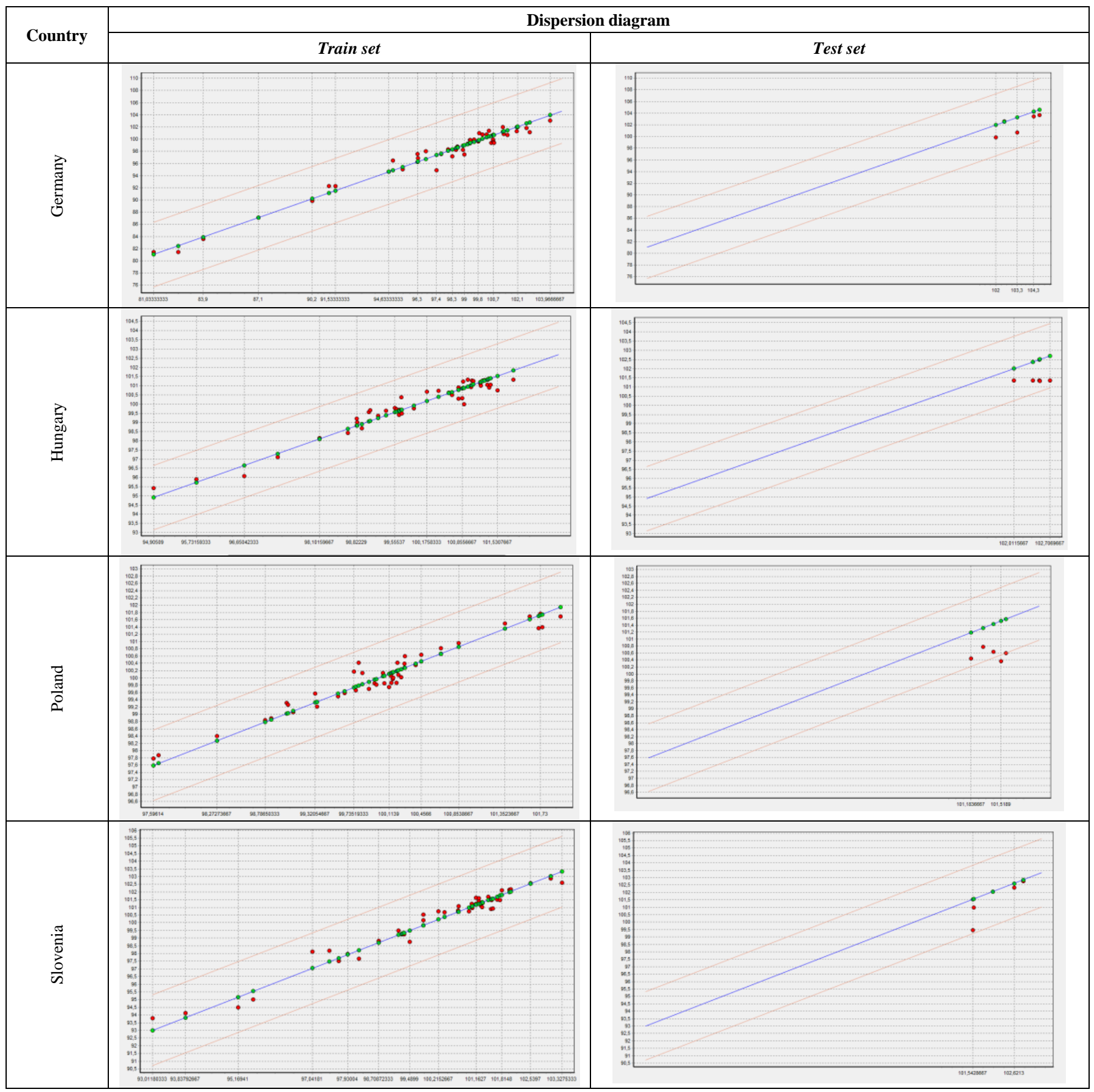


According to the type of neural network and to the results of the correlation analysis, these seven indicators for predicting the BCI of Germany, which influence the business confidence index, were: Unemployment Rate (UR_Germany), GDP Annual Growth Rate (GDP_AGR_Germany), New Orders (NO_Germany), Consumer Spending (CS_Germany), Export (Exports_Germany), Import (Imports_Germany), Industrial production (IP_Germany). For Hungary, there are eight indicators - Unemployment Rate (UR_Hungary), GDP (Annual Growth Rate) (GDP_AGR_Hungary), New Orders (NO_Hungary), Consumer Spending (CS_Hungary), Export (Exports_Hungary), Import (Imports_Hungary), Industrial production (IP_Hungary), Steel Production (SP_Hungary). For Poland, there are five indicators - GDP Annual Growth Rate (GDP_AGR_Poland), New Orders (NO_Poland), Export (Exports_Poland), Import (Imports_Poland), Industrial production (IP_Poland). For Slovenia, there are four indicators - GDP Annual Growth Rate (GDP_AGR_Slovenia), Export (Exports_Slovenia), Import (Imports_Slovenia), Industrial production (IP_Slovenia).

From the dispersion diagram (Table I), it can be seen that for all investigated countries, the predicted values of BCI do not exceed 5\% confidence interval (green markers on the dispersion diagram indicate input values, red ones predicted values). For Poland only, there is one case, when the predicted value of the test set exceeds the limits of the confidence interval. But despite this, the obtained neural

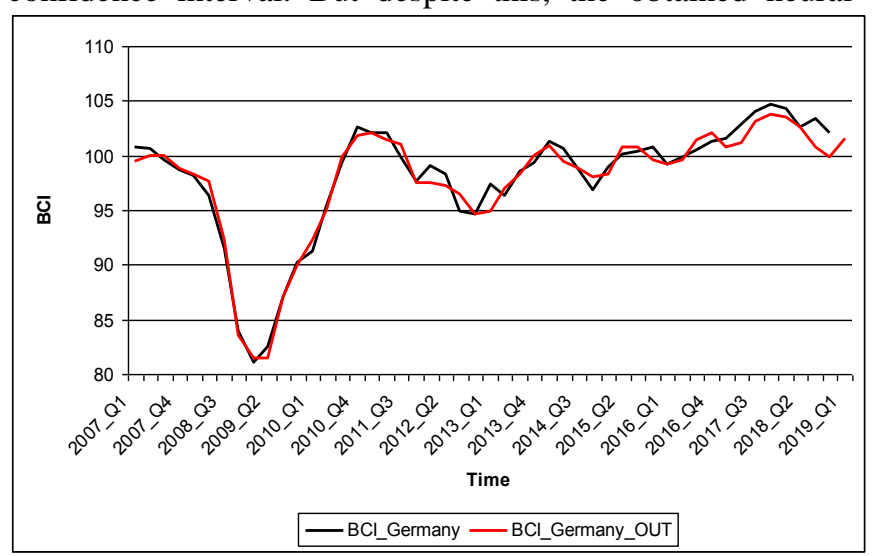

a) Germany

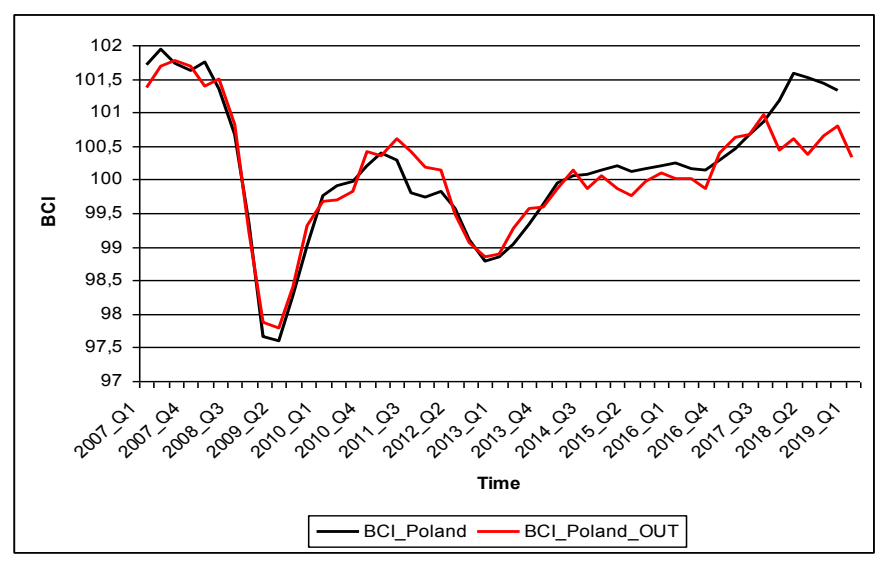

c) Poland network model showed good results in testing and assessing the accuracy of the forecast (Table II), so we can conclude that the neural network models obtained are qualitative.

Average errors train and test sets for all models are not exceed the recognition error threshold (0.05), which evidenced that the resulting neural network models can be used to predict the index of business confidence for the corresponding country. Mean squared error and absolute percentage error also evidenced about high forecasting quality, since they are not exceed $10 \%$.

TABLE II. MEASURES OF THE FORECAST SET

\begin{tabular}{|l|c|c|c|c|}
\hline \multirow{2}{*}{ Measures } & \multicolumn{4}{c|}{ Country } \\
\cline { 2 - 5 } & Germany & Hungary & Poland & Slovenia \\
\hline Average train error & 0.00162 & 0.00293 & 0.00277 & 0.00172 \\
\hline Average test error & 0.00489 & 0.02469 & 0.03981 & 0.00882 \\
\hline Mean squared error (MSE) & 0.00047 & 0.00272 & 0.01061 & 0.00195 \\
\hline $\begin{array}{l}\text { Absolute percentage error } \\
\text { (MAPE), \% }\end{array}$ & 0.797 & 0.373 & 0.252 & 0.358 \\
\hline
\end{tabular}

Using the worked out neural network models, we construct the forecast of the business confidence index for the investigated countries for the $1^{\text {st }}$ quarter of 2019. This forecast was made using the "What - If" tool of the analytical platform Deductor Studio Academic 5.3. The forecast result is shown in Figure 2.

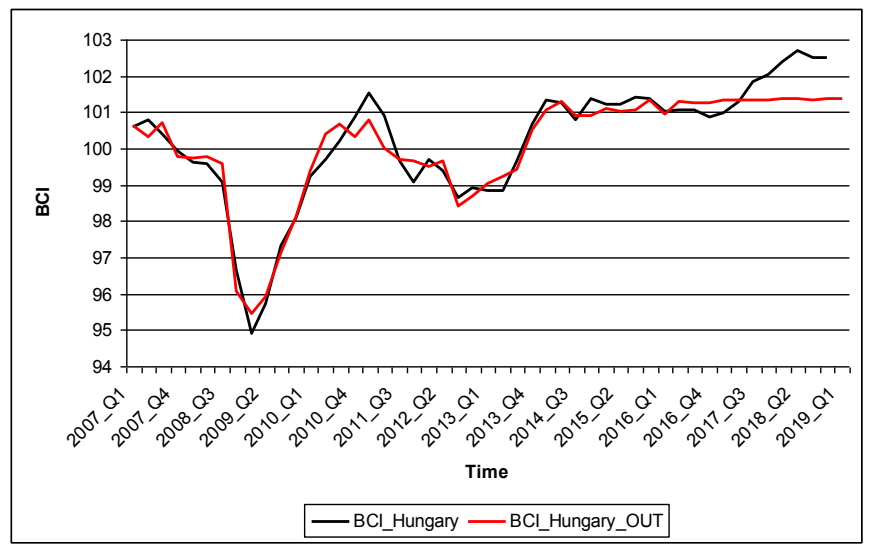

b) Hungary

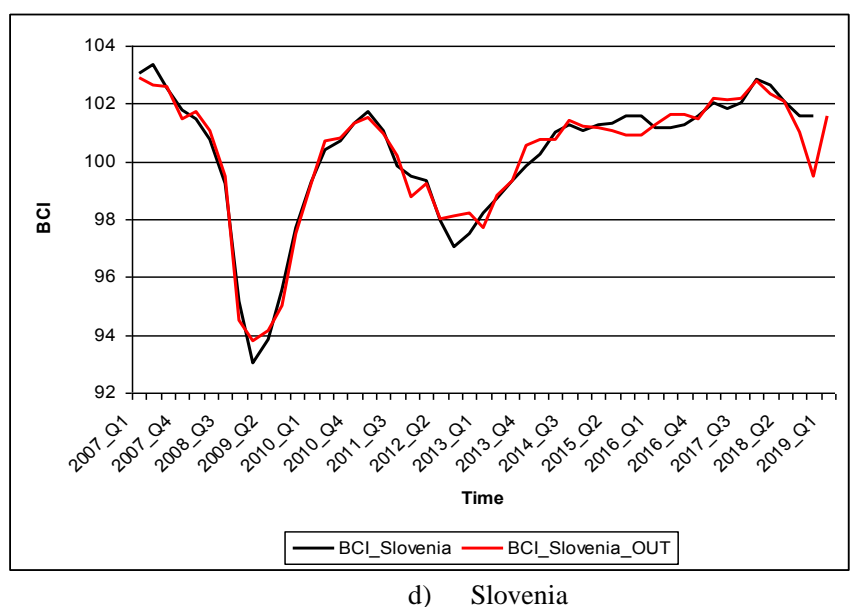

d) Slovenia

Fig. 2. The result of forecasting the business confidence index based on neural network technologies 
Based on a visual analysis of the real and forecast values of the business confidence index (Figure 2), we can conclude that the obtained forecasts completely repeat the trends of the original time series. The forecast value of the business confidence index of German entrepreneurs in $1^{\text {st }}$ quarter 2019 decrease by $0.41 \%$ compared to $4^{\text {th }}$ quarter 2018 (from 102 to 101.58). The decline in the value of BCI is associated with an increase in the rate of growth in imports by $50.11 \%$ (from 4.93 in $4^{\text {th }}$ quarters of 2018 to 7.4 in $1^{\text {st }}$ quarter of 2019) and an increase in the rate of unemployment by $3.63 \%$ (from 3.3 in $4^{\text {th }}$ quarters of 2018 to 3.42 in $1^{\text {st }}$ quarter of 2019).

In accordance with the forecast of the business confidence index of Hungarian's entrepreneurs in the $1^{\text {st }}$ quarter of 2019 decrease by $1.05 \%$ compared to $4^{\text {th }}$ quarter of 2018 (from 102.50 to 101.38). This is due to the decline of expectations in the industry, namely the fall in the rate of growth in the steel production by $157.72 \%$ in the period that is being considered.

Poland is an import-dependent country, so a decline in rate of growth in import by $53.83 \%$ in $1^{\text {st }}$ quarter of 2019 compared to $4^{\text {th }}$ quarter of 2018 leads to a decrease of $0.99 \%$ in the business confidence index of Polish entrepreneurs (from 101.32 to 100.32 points, respectively).

The forecast value of the BCI of Slovakia in $1^{\text {st }}$ quarter 2019 practically does not change (101.56 points versus 101.54 points in $4^{\text {th }}$ quarter 2018 ). But at the same time, in the period that is being considered, a decrease in the growth rate of imports by $31.64 \%$ is observed, which a positive factor for this country is.

Thus, in this research, the proposed methodological approach to predicting BCI based on neural network technologies was tested on four countries data. This toolkit makes it possible to take into account the most significant factors for predicting indicator and the results are highly accurate.

\section{CONCLUSIONS}

This research is devoted to forecasting of the country's business climate based on the use of the appropriate indicator - the business confidence index (BCI), which determines the efficiency of the country's economy and its development prospects. The advantages of the indicator are the fact that it has a proactive publication nature; therefore it is valuable for forecasting the macroeconomic state of the country.

Since neural network technologies are currently characterized by broad research capabilities, it is proposed to make BCI forecast by phased construction of a neural network model with the capabilities of its training. According to the results of approbation of the proposed methodological approach, the predicted time series of quarterly values of the BCI indicator in Germany, Hungary, Poland, Slovenia for the period 2007-2018, taking into account the influence of close socio-economic indicators by the type of relation, in particular: Producer Price, Unemployment Rate, GDP Annual Growth Rate, New Orders, Consumer Spending, Changes in Inventories,
Exports, Imports, Industrial Production and Steel Production.

According to the results of the correlation analysis was build several types of the neural network, such as: for predicting the BCI of Germany - [7-2-1], Hungary - [8-21], Poland - [5-2-1], Slovenia - [4-2-1]. The first numeral is the number of variables in the input layer, second numeral - number of neurons in the hidden layer, the last number is output layer.

The results of forecasting based on the absolute percentage error (MAPE) are determined to be exact, and such that they are within the limits of the confidence interval. It is proved that in the next period the value of the business confidence index for Germany will be 101.58, Hungary -101.38 , Poland -100.32 , Slovenia - 101.56. The obtained forecast indicators are the basis for making management decisions both at the level of business entities and at the macro level. In addition, the advanced nature of the BCI makes it possible at the same time to be an instrument of strategic planning and an instrument of regulation of the current tactics and strategy, which, in general, determines the prospects of investigating its dynamics and structure, the factors that influence them. The results of these investigates in the future allow us to justify the micro- and macroeconomic strategies for the development of socio-economic systems, the base of which are the prognostic data of business confidence index.

\section{REFERENCES}

[1] H. F. de Mendonca, and A. F. G. Almeida, "Importance of credibility for business confidence: evidence from an emerging economy", Empirical Economics, 2018. Doi: 10.1007/s00181-018-1533-5

[2] H. Sakaji, R. Kuramoto, H. Matsushima, K. Izumi, T. Shimada, and K. Sunakawa, "Financial Text Data Analytics Frameworkfor Business Confidence Indices and Inter-Industry Relations", Proceedings of the First Workshop on Financial Technology and Natural Language Processing (FinNLP@IJCAI 2019), Macao, China, August 12, 2019, pp. $40-46$

[3] S. Feuerriegela, and J. Gordon, "News-based forecasts of macroeconomic indicators: A semantic path model for interpretable predictions", European Journal of Operational Research, vol. 272, no. 1, pp. 162-175, January, 2019. Doi: 10.1016/j.ejor.2018.05.068

[4] V. Los, and D. Ocheretin "Construction of business confidence index based on a system of economic indicators", SHS Web of Conferences, vol.65, 2019. Doi: 10.1051/shsconf/20196506003

[5] S. Arslankaya and V. Öz "Time Series Analysis on Sales Quantity in an Automotive Company and Estimation by Artificial Neural Networks", Sakarya University Journal of Science,no. 22 (5), pp. 1482-1492, 2018. Doi:10.16984/saufenbilder.456518

[6] OECD Data: Leading indicators - Business Confidence Index (BCI), 2019. [Online]. Available:https://data.oecd.org/leadind/businessconfidence-index-bci.htm. Accessed on:July 8, 2019.

[7] Tradingeconomics.com: 20 million indicators from 196 countries, 2019. [Online]. Available: https://tradingeconomics.com. Accessed on:July 8, 2019.

[8] Y. Bilan, B. Gavurova, S. Gedek, and A. Tkacova, "The Composite Coincident Indicator (CCI) for business cycles", Acta Polytechnica Hungarica, vol. 14, no. 7, pp. 71-90, 2017. Doi: 10.12700/APH.14.7.2017.7.5

[9] N. B. Paklin, and V. I. Oreshkov, Biznes-analitika: ot dannyh $k$ znanijam.[Business Analytics: From Data to Knowledge].Saint Petersburg, The Russian Federation:Piter, 2013

[10] R. Callan, The Essence of Neural Network. New Jersey,The USA: Prentice Hall, 1999 